\title{
Mechanism of endothelial cyto-protective and thrombo-resistance effects of sildenafil, vardenafil and tadalafil in male rabbit
}

\author{
Mohamed-I Kotb El-Sayed, Hatem Al-Kordy A. Amin
}

Department of Biochemistry and Molecular Biology, Faculty of Pharmacy, Helwan University, Cairo, Egypt

Submitted: 20 December 2012

Accepted: 2 February 2013

Arch Med Sci 2015; 11, 1: 190-198

DOI: 10.5114/aoms.2013.33616

Copyright $\odot 2015$ Termedia \& Banach

\section{Abstract}

Introduction: PDE5 inhibitors (PDE5 ${ }_{\text {inhs }}$ ) have proven to be of great impact in the treatment of numerous human extra-sexual diseases and their chronic use may induce endothelial rehabilitation. This study aimed to assess the effects of $\mathrm{PDE}_{\text {inhs }}$ at chronic administration to explore the possible endothelial cyto-protective and thrombo-resistance effects.

Material and methods: One hundred New Zealand white male rabbits were divided into four groups. The first group (control, C) received $1 \mathrm{ml}$ saline $/ \mathrm{kg}$, the second group (S) received $10 \mathrm{mg} / \mathrm{kg}$ sildenafil, the third group (V) received $2 \mathrm{mg} / \mathrm{kg}$ vardenafil, and the fourth group $(\mathrm{T})$ received $2 \mathrm{mg} / \mathrm{kg}$ tadalafil in saline I.P. three times weekly for 4 weeks. Blood samples were collected and plasma was isolated for determination of 2,3-dinor-6-keto-prostaglandin F-1 $\alpha\left(\mathrm{PGF}_{1 \alpha}\right)$, 11-dehydro$\mathrm{TXB}_{2}\left(\mathrm{TXB}_{2}\right)$, fibrinogen, calcium levels, prothrombin (PT), and thrombin times (TT). Results: PDE5 $5_{\text {inhs }}$ significantly increase $\mathrm{PGF}_{1 \alpha}$, calcium levels, PT and TT $(p<0.001)$ when compared with baseline data or with the saline group at the end of treatment. In contrast, PDE5 ${ }_{\text {inhs }}$ significantly decrease TXB2 and fibrinogen levels $(p<0.001)$ when compared either with their baseline data or with the saline group at the end of treatment. The tadalafil group showed a lower increase in $\mathrm{PGF}_{1 \alpha}(p<0.001)$, lower decrease in $\operatorname{TXB}_{2}(p<0.001)$, and higher increase in calcium levels $(p<0.01, p<0.05)$, lower increase in PT and TT levels $(p<0.001)$ when compared with sildenafil or vardenafil.

Conclusions: The prolonged use of PDE $5_{\text {inhs }}$ has time-dependent mild to moderate endothelial cyto-protective, thrombo-resistance anti-inflammatory and antinociception effects via activation of endothelial NOS (eNOS), increase of $\mathrm{PGI}_{2}$ synthesis and decrease of fibrinogen with significant increase in PT and TT.

Key words: phosphodiesterase-5 inhibitors, cyto-protective, thrombo-resistance, prostacyclin, thromboxane $A_{2}$.

\section{Introduction}

Erectile dysfunction (ED) could be a manifestation of increased risk for cardiovascular diseases due to loss of endothelial cell (EC) integrity resulting in endothelial cell dysfunction (EDys) affecting vessel walls and circulation [1]. Intact ECs inactivate plasminogen activator inhibitor-1 (PAI-1) through binding thrombin resulting in protein-C activation; therefore ECS works as an anticoagulant membrane [2].

Prostacyclin $\left(\mathrm{PGI}_{2}\right)$, tissue plasminogen and nitric oxide (NO) are synthesized and released from intact ECs, which enables ECs to have a cru-

\author{
Corresponding author: \\ Dr Mohamed-I Kotb El-Sayed \\ Department of Biochemistry \\ and Molecular Biology \\ Faculty of Pharmacy \\ Helwan University \\ Ain Helwan \\ Helwan P.O. Box 11790 \\ Cairo, Egypt \\ Phone: +20114-0400-767 \\ Fax: +202-2554-1601 \\ E-mail: \\ mohamed.kotb71524@ \\ gmail.com, \\ mohamed.kotb@ \\ pharm.helwan.edu.eg
}


cial role in thrombosis control [3]. Nitric oxide is synthesized from the amino acid L-arginine by nitric oxide synthase (NOS) [4].

Endothelial cell dysfunction induce platelet activation releasing thromboxane $\mathrm{A} 2\left(\mathrm{TXA}_{2}\right)$ to promote platelet aggregation and coagulation triggering vasoconstriction which is counteracted by $\mathrm{PGI}_{2}$, and this explains the altered $\mathrm{TXA}_{2} / \mathrm{PGI}_{2}$ ratio and thrombosis formation in cardiovascular and cerebrovascular diseases [3, 5-7].

At least 11 phosphodiesterase-5 enzyme (PDE5) families have been identified and characterized for their tissue, substrates and drug specificity. Phosphodiesterase-5 enzyme inhibitors (PDE5 ${ }_{\text {inhs }}$ ) such as sildenafil, vardenafil and tadalafil are widely used in male ED treatment. They increase the intracellular cGMP level by inhibition of PDE5 and enhancement of nitric oxide (NO), leading to corpus cavernosum smooth muscle relaxation and improved penile erection [8].

PDE5 $5_{\text {inhs }}$ have proven effective in treatment of several human extra-sexual diseases and their chronic use might induce endothelial rehabilitation and amelioration of endothelial dysfunction, hemodynamics and exercise tolerance improvement. They have been investigated for the treatment of several extra-sexual diseases including pulmonary hypertension and asthma in lungs, ischemic acute stroke and systemic inflammation, and their clinical effects were approved for treating several cardiovascular and chronic obstructive pulmonary diseases [9-11]. Regardless of the ED degree, chronic therapy for four weeks with tadalafil in ED patients with cardiovascular risk improved their endothelial function and after therapy discontinuation this clinical effect lasted for at least 2 weeks [12]. PDE5 ${ }_{\text {inhs }}$ are dose dependent with variable half-maximal inhibition $\left(I_{50}\right)$; sildenafil is mostly selective for PDE5 (at $3.5 \mathrm{nmol} / \mathrm{I} I \mathrm{C}_{50}$ concentration), retinal PDE6 (at 34 to $38 \mathrm{nmol} / \mathrm{I} I C_{50}$ concentration), PDE1 (at $280 \mathrm{nmol} / \mathrm{IIC} \mathrm{C}_{50}$ concentration) and PDE2,4,7-11 (at $>2600 \mathrm{nmol} / \mathrm{I} \mathrm{IC} 50$ concentration) [13].

In this study we aim to assess the effects of commonly and widely used PDE $5_{\text {inhs }}$ (at chronic administration) on $\mathrm{PGI}_{2}, \mathrm{TXA}_{2}$, fibrinogen, calcium and coagulation parameters in order to explore the possible extra-sexual therapeutic effects - endothelial cytoprotection, thrombo-resistance, anti-inflammatory and anti-nociception - in male rabbits.

\section{Material and methods}

\section{Chemicals, reagents, and equipment}

All drugs were purchased from Sigma-Aldrich (St Louis, USA) unless otherwise indicated. Sildenafil (Viagra 100 mg; Pfizer), tadalafil (Cialis 20 mg; Eli Lilly, Indianapolis, Indiana), and vardenafil (Levitra 20 mg; Schering-Plough, Kenilworth, New Jersey) solutions were prepared according to Behn and Potter [14]. Tablets were ground into a fine powder and mixed with saline then filtered twice through $40 \mu \mathrm{m}$ filters and the filtered solution was chilled at $4^{\circ} \mathrm{C}$. Working solutions used to prepare doses were brought to room temperature $2 \mathrm{~h}$ before injections.

Kits for measuring TXA2 stable metabolite [11dehydro thromboxane $B_{2}$ (Cayman, Cat. No. = 519510)] and $\mathrm{PGI}_{2}$ stable metabolite [2,3-dinor-6keto prostaglandin F1 $\alpha$ (Cayman, Cat. No. = 515121)] were used. Ultra Pure water free of organic contaminant traces and deionized was used to prepare all ELISA reagents and buffers (Ultra Pure) (Cayman Item No. $=400000)$. Calcium was measured by colorimetric kit (QCA company ref. 99-59-36).

Plate ELISA reader (Humareader Human Company $2106 / 1682$ ) capable of measuring absorbance at $405-420 \mathrm{~nm}$, and adjustable pipettes. Centrifuge 6000 rpm (Hitachi, Germany), syringes, Vacutainer tubes, tourniquet, Eppendorf tubes, micropipettes, plastic tubes, and cylinders. Coagulometer (Biomatic Biosarstedt, Freiburg, Germany) and UV/visible spectrophotometer (Shimadzu).

\section{Animals}

To define the minimum total sample size and the average number for each group the a priori test with the following parameters was conducted: anticipated effect size (Cohen's $d$ ): 0.7; desired statistical power level: 0.8; probability level: 0.05 . The a priori test calculation returned the following values: minimum total sample size (one-tailed hypothesis): 52; minimum sample size per group (one-tailed hypothesis): 26.

According to a priori test results, experiments were conducted on 100 male New Zealand white rabbits with body weight range $1.8-2.1 \mathrm{~kg}$ and at 6 or 7 months of age. The animals were maintained in aluminium cages in an animal room under controlled conditions of temperature, relative humidity, and ventilation. Animals were fed ad libitum with standard laboratory chow and allowed free access to water. This investigation conforms to the ethical Guide for the Care and Use of Laboratory Animals published by the US National Institutes of Health (NIH Publication No. 85-23, revised in 1996).

\section{Experimental protocols}

After a 1 week acclimation period, the animals were fasted for $24 \mathrm{~h}$ before starting the experiments. Animals were assigned to four groups, 25 animals in each group. The first group (Control, C) received $1 \mathrm{ml} / \mathrm{kg}$ saline (I.P.), the second group (S) received $10 \mathrm{mg} / \mathrm{kg}$ sildenafil in saline (I.P.), the third group $(\mathrm{V})$ received $2 \mathrm{mg} / \mathrm{kg}$ vardenafil in saline (I.P), and the fourth group ( $\mathrm{T}$ ) received $2 \mathrm{mg} / \mathrm{kg}$ tadalafil in saline (I.P.) three times weekly for 4 weeks $[15,16]$. 
The animal protocol is in accordance with the Animal Ethical Care regulations in the Faculty of Pharmacy, Helwan University.

\section{Biochemical assay}

The blood samples were obtained from the auricular arteries while the animals were in a fasting state before experimentation (day 0 ) and at 2 and 4 weeks after PDE5 ${ }_{\text {inhs }}$ injection. The blood samples from each animal were collected and the first 3-ml aliquot of blood was taken on sodium heparinised sampling vials for plasma separation to be refrigerated at $-20^{\circ} \mathrm{C}$ until used for measuring of $\mathrm{PGI}_{2}$ stable metabolite, 2,3-dinor-6-keto-prostaglandin F-1 $\alpha$ (2,3-dinor-6-keto-PGF-1 $\alpha$ ) [17], 11-dehydrothromboxane $B_{2}$ (11-dehydro-TXB ${ }_{2}$, a stable metabolite of $\mathrm{TXA}_{2}$ ) [18] by enzyme immunoassay, and calcium was estimated by the O-cresolphthalein direct method using a colorimetric kit (QCA company ref. 99-59-36) [19]. The second 3-ml aliquots of blood samples were taken into citrated blood sampling vials and immediately sent to the lab to be assayed immediately after collection, for measuring fibrinogen levels $(\mathrm{mg} / \mathrm{dl})$ using modified Clauss assay [20], prothrombin time (PT), and thrombin time (TT) as described by Dacie and Lewis [21] using a coagulometer (an automated system in which the formation of the clot is detected electronically) (Biomatic Biosarstedt, Freiburg, Germany).

\section{Statistical analysis}

Data for the parameters are presented as the means \pm S.E.M. of the values recorded in each group. The above parameters were analyzed using a oneway analysis of variance (ANOVA), with Tukey post hoc correction for multiple comparisons being performed; a probability level of $p<0.05$ was regarded as significant (using InStat3 version software).

\section{Results}

PDE5 $5_{\text {inhs }}$ (sildenafil, tadalafil, and vardenafil) were injected intra-peritoneally into rabbits to be compared with saline for their effects on $P G I_{2}, T_{X A_{2}}$, fibrinogen, calcium levels, PT and TT to assess additional extra-sexual effects.

Data of the current study showed that PDE $5_{\text {inhs }}$ significantly increase 2,3-dinor-6-keto prostaglandin $\mathrm{F}_{1 \alpha}$ (as $\mathrm{PGI}_{2}$ stable metabolite) levels when compared either with their baseline data or with the saline group at the end of treatment. The tadalafil group showed a lower increase in 2,3-dinor-6-keto prostaglandin $F_{1 \alpha}$ when compared either with sildenafil or vardenafil. In contrast, PDE5 ${ }_{\text {inhs }}$ significantly decrease 11-dehydro-TXB (as TXA $_{2}$ stable metabolite) levels when compared either with their baseline data or with the saline group at the end of treatment. The tadalafil group showed a lower decrease in 11-dehydro- $T \mathrm{XB}_{2}$ when compared with either sildenafil or vardenafil (data shown in Table I, Figure 1).

Data of the present study showed that PDE $5_{\text {inhs }}$ significantly increase plasma calcium levels, PT and TT when compared either with their baseline data or with the saline group at the end of treatment. The tadalafil group showed a slightly higher increase in calcium levels and lower increase in PT or TT when compared with either sildenafil or vardenafil. In contrast, PDE $5_{\text {inhs }}$ significantly decrease fibrinogen levels when compared either with their baseline data or with the saline group at the end of treatment (data shown in Table II, Figure 2). The postulated mechanisms of PDE $5_{\text {inhs }}$ are presented diagrammatically in Figure 3.

\section{Discussion}

PDE5 $5_{\text {inhs }}$ have proven effective in treatment of several human extra-sexual diseases and endothe-

Table I. Effects of PDE5 ${ }_{\text {inhs }}$ on 2,3-dinor-6-keto prostaglandin $\mathrm{F}_{1 \alpha}$ and 11-dehydro-TXB 2 plasma levels in rabbit

\begin{tabular}{|c|c|c|c|c|c|}
\hline Variables & $\begin{array}{c}\text { Time/ } \\
\text { treatment }\end{array}$ & $\begin{array}{c}\text { Saline } \\
(1 \mathrm{ml} / \mathrm{kg} \\
\text { I.P./triweekly/ } \\
4 \text { weeks }) \\
(n=25)\end{array}$ & $\begin{array}{c}\text { Sildenafil } \\
(10 \mathrm{mg} \text { in } 1 \mathrm{ml} \\
\text { saline } / \mathrm{kg} \\
\text { I.P. triweekly } \\
\text { for } 4 \text { weeks }) \\
(n=25)\end{array}$ & $\begin{array}{l}\text { Vardenafil } \\
(2 \mathrm{mg} \text { in } 1 \mathrm{ml} \\
\text { saline } / \mathrm{kg} \\
\text { I.P. triweekly } \\
\text { for } 4 \text { weeks }) \\
(n=25)\end{array}$ & $\begin{array}{c}\text { Tadalafil } \\
(2 \mathrm{mg} \text { in } 1 \mathrm{ml} \\
\text { saline } / \mathrm{kg} \\
\text { I.P. triweekly } \\
\text { for } 4 \text { weeks }) \\
(n=25)\end{array}$ \\
\hline \multirow{3}{*}{$\begin{array}{l}\text { Plasma } \\
\text { 2,3-dinor-6-keto } \\
\text { prostaglandin } \mathrm{F}_{1 \alpha} \\
{[\mathrm{pg} / \mathrm{ml}]}\end{array}$} & $0-W$ & $3.98 \pm 0.12$ & $4.22 \pm 0.14$ & $4.35 \pm 0.11$ & $4.36 \pm 0.12$ \\
\hline & $2-W$ & $4.13 \pm 0.10$ & $8.87 \pm 0.31$ & $9.36 \pm 0.25$ & $6.28 \pm 0.27$ \\
\hline & $4-W$ & $4.12 \pm 0.14$ & $11.85 \pm 0.30 \star \star \star, \nabla \nabla \nabla$ & $12.80 \pm 0.31 \star \star \star, \nabla \nabla \nabla$ & $6.53 \pm 0.28 \star \star \star, \nabla \nabla \nabla, \bullet \bullet \bullet, \Phi \Phi \Phi$ \\
\hline \multirow{3}{*}{$\begin{array}{l}\text { Plasma } \\
\text { 11-dehydro-TXB } 2 \\
{[\mathrm{pg} / \mathrm{ml}]}\end{array}$} & $0-W$ & $1.75 \pm 0.056$ & $1.66 \pm 0.064$ & $1.58 \pm 0.11$ & $1.70 \pm 0.061$ \\
\hline & $2-W$ & $1.73 \pm 0.055$ & $1.27 \pm 0.045$ & $1.20 \pm 0.07$ & $1.47 \pm 0.067$ \\
\hline & $4-W$ & $1.74 \pm 0.058$ & $0.94 \pm 0.060 \star \star \star, \nabla \nabla \nabla$ & $0.89 \pm 0.06^{\star \star \star, \nabla \nabla \nabla}$ & $1.38 \pm 0.058^{\star}, \nabla \nabla, \bullet \bullet, \Phi \Phi \Phi$ \\
\hline
\end{tabular}


A

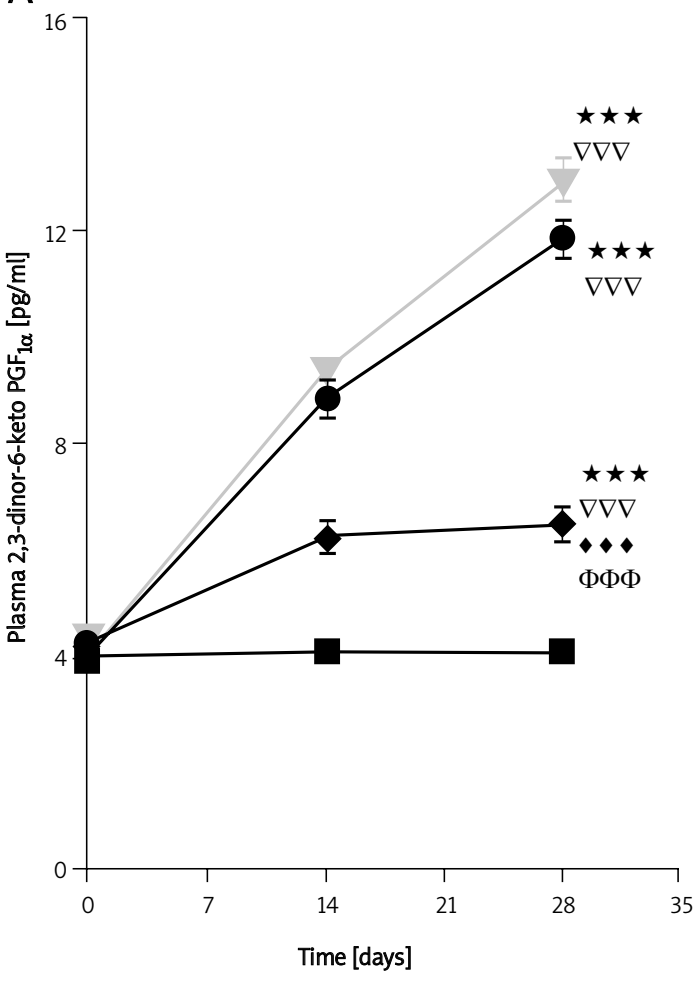

B

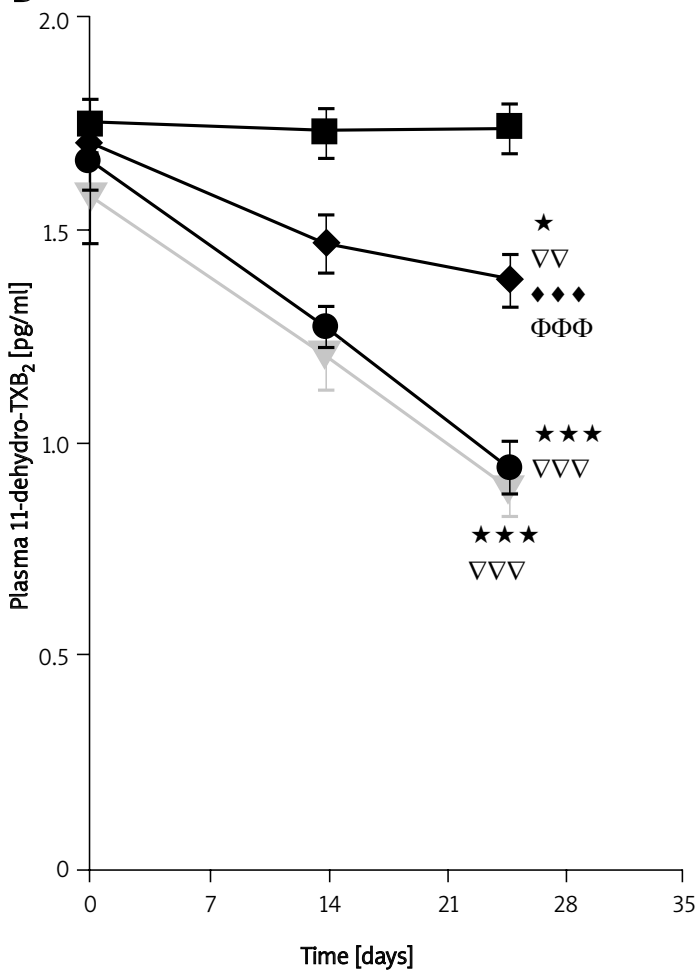

Figure 1. Effects of phosphodiestrase-5-inhibitors on 2,3-dinor-6-keto prostaglandin $F_{1 \alpha}(A)$ and 11-dehydro-TXB $(B)$ plasma levels in rabbit

Each value represents mean \pm S.E.M. ${ }^{\star}$ Comparing each group at $4 W$ vs. baseline ( 0 day), $\nabla$ Comparing all tested groups at $4 W$ vs. con trol (saline) at $4 W,-$ Comparing vardenafil or tadalafil group at $4 W$ vs. sildenafil group at $4 W, \Phi$ Comparing tadalafil group at $4 W$ vs. vardenafil group at $4 W,{ }^{\star} p<0.05, \nabla \nabla p<0.01,{ }^{\star} \star \star, \nabla \nabla \nabla, \bullet \bullet, \Phi \Phi \Phi_{p}<0.001$. PDE5 $5_{\text {inhs }}-$ phosphodiesterase-5-inhibitors, $W-$ weeks.

Table II. Effects of PDE5 ${ }_{\text {inhs }}$ on coagulation parameters and calcium in rabbit

\begin{tabular}{|c|c|c|c|c|c|}
\hline Variables & $\begin{array}{c}\text { Time/ } \\
\text { treatment }\end{array}$ & $\begin{array}{c}\text { Saline } \\
(1 \mathrm{ml} / \mathrm{kg} \\
\text { I.P./tri-weekly/ } \\
4 \text { weeks }) \\
(n=25)\end{array}$ & $\begin{array}{c}\text { Sildenafil } \\
(10 \mathrm{mg} \text { in } 1 \mathrm{ml} \\
\text { saline/kg } \\
\text { I.P. triweekly } \\
\text { for } 4 \text { weeks }) \\
(n=25)\end{array}$ & $\begin{array}{l}\text { Vardenafil } \\
(2 \mathrm{mg} \text { in } 1 \mathrm{ml} \\
\text { saline/kg } \\
\text { I.P. triweekly } \\
\text { for } 4 \text { weeks) } \\
(n=25)\end{array}$ & $\begin{array}{c}\text { Tadalafil } \\
\text { ( } 2 \mathrm{mg} \text { in } 1 \mathrm{ml} \\
\text { saline/kg } \\
\text { I.P. triweekly } \\
\text { for } 4 \text { weeks) } \\
(n=25)\end{array}$ \\
\hline \multirow[t]{3}{*}{ Calcium [mg/dl] } & $0-W$ & $14.13 \pm 0.23$ & $14.20 \pm 0.29$ & $14.05 \pm 0.22$ & $14.20 \pm 0.28$ \\
\hline & $2-W$ & $14.14 \pm 0.19$ & $15.10 \pm 0.28$ & $15.02 \pm 0.27$ & $15.28 \pm 0.25$ \\
\hline & $4-W$ & $14.23 \pm 0.16$ & $16.02 \pm 0.32 \star \star \star, \nabla \nabla \nabla$ & $16.17 \pm 0.25^{\star \star \star \star, \nabla \nabla \nabla}$ & $17.42 \pm 0.21^{\star \star \star} \star \nabla \nabla \nabla, \bullet \bullet, \Phi$ \\
\hline \multirow[t]{3}{*}{ Fibrinogen $[\mathrm{mg} / \mathrm{dl}]$} & $0-W$ & $252.44 \pm 3.31$ & $253.68 \pm 3.50$ & $253.64 \pm 3.05$ & $255.36 \pm 3.23$ \\
\hline & $2-W$ & $253.80 \pm 3.20$ & $189.80 \pm 4.83$ & $194.12 \pm 2.80$ & $217.56 \pm 4.07$ \\
\hline & $4-W$ & $254.92 \pm 3.06$ & $179.32 \pm 4.13 \star \star \star, \nabla \nabla \nabla$ & $182.20 \pm 3.60 \star \star \star, \nabla \nabla \nabla$ & $195.04 \pm 8.22^{\star \star \star, \nabla \nabla \nabla}$ \\
\hline \multirow{3}{*}{$\begin{array}{l}\text { Prothrombin time } \\
\text { (PT) [s] }\end{array}$} & $0-W$ & $9.32 \pm 0.25$ & $9.28 \pm 0.18$ & $9.40 \pm 0.29$ & $9.48 \pm 0.36$ \\
\hline & $2-W$ & $9.24 \pm 0.19$ & $18.80 \pm 0.52$ & $19.16 \pm 0.69$ & $13.92 \pm 0.43$ \\
\hline & $4-W$ & $9.48 \pm 0.19$ & $29.52 \pm 0.80 \star \star \star, \nabla \nabla \nabla$ & $26.32 \pm 1.03 \star \star \star, \nabla \nabla \nabla, \bullet 1$ & $17.40 \pm 0.64 \star \star \star, \nabla \nabla \nabla, \bullet \bullet \bullet, \Phi \Phi \Phi$ \\
\hline \multirow{3}{*}{$\begin{array}{l}\text { Thrombin time } \\
\text { (TT) [s] }\end{array}$} & $0-W$ & $18.20 \pm 0.33$ & $18.32 \pm 0.35$ & $18.60 \pm 0.53$ & $18.52 \pm 0.54$ \\
\hline & $2-W$ & $18.32 \pm 0.33$ & $28.60 \pm 0.71$ & $27.36 \pm 0.74$ & $23.32 \pm 0.67$ \\
\hline & $4-W$ & $18.36 \pm 0.35$ & $36.12 \pm 0.78 \star \star \star, \nabla \nabla \nabla$ & $34.20 \pm 0.87 \star \star \star, \nabla \nabla \nabla 2$ & $27.28 \pm 0.72 \star \star \star, \nabla \nabla \nabla, \bullet \bullet, \Phi \Phi \Phi$ \\
\hline
\end{tabular}

Abbreviations - see Table I; $\Phi_{p}<0.05, \cdots p<0.01$. 

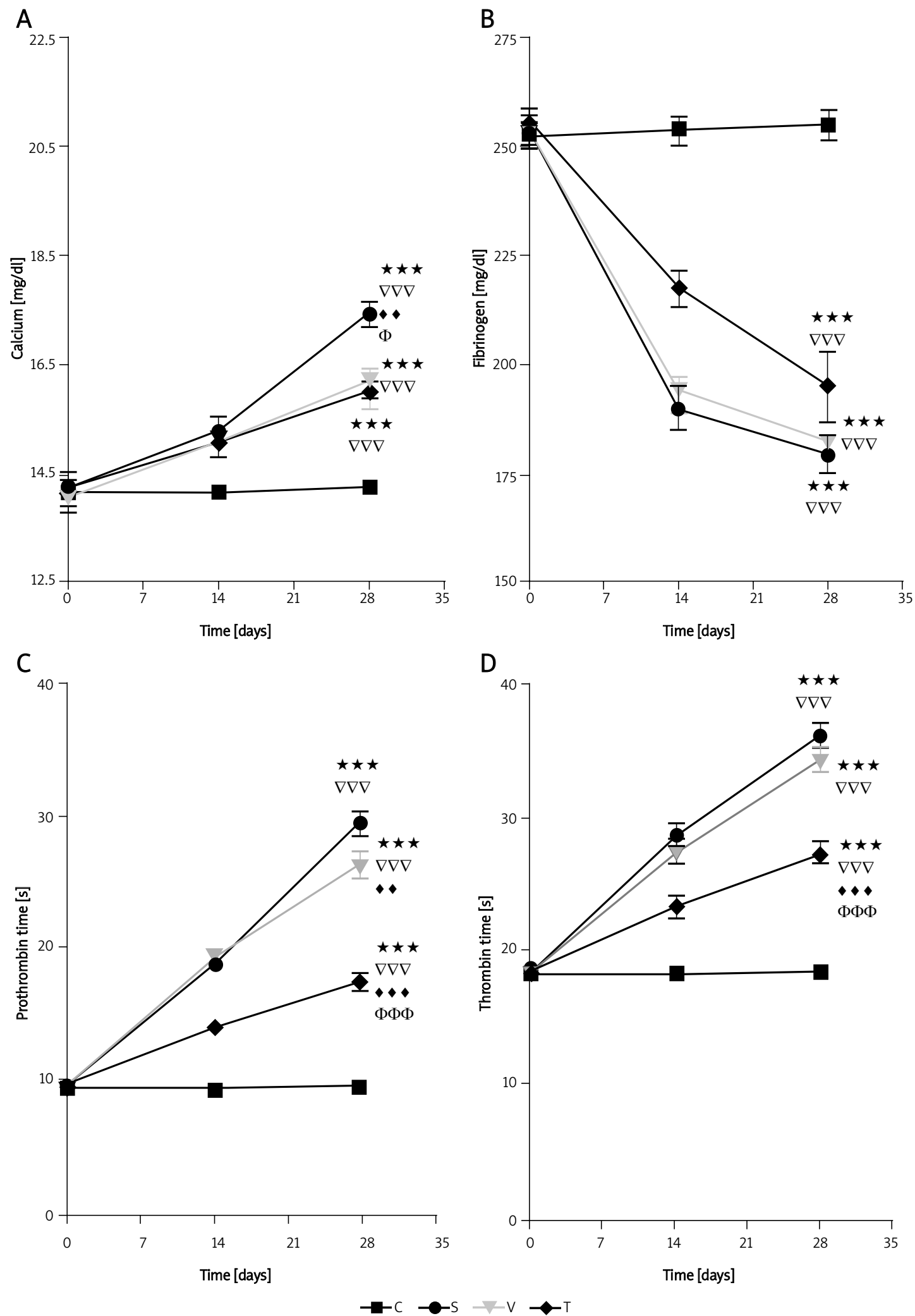

Figure 2. Effects of phosphodiestrase-5-inhibitors on calcium (A), fibrinogen (B), prothrombin (C) and thrombin (D) times in rabbit

Abbreviations - see Table I; $\Phi_{p}<0.05, \cdots p<0.01$. 


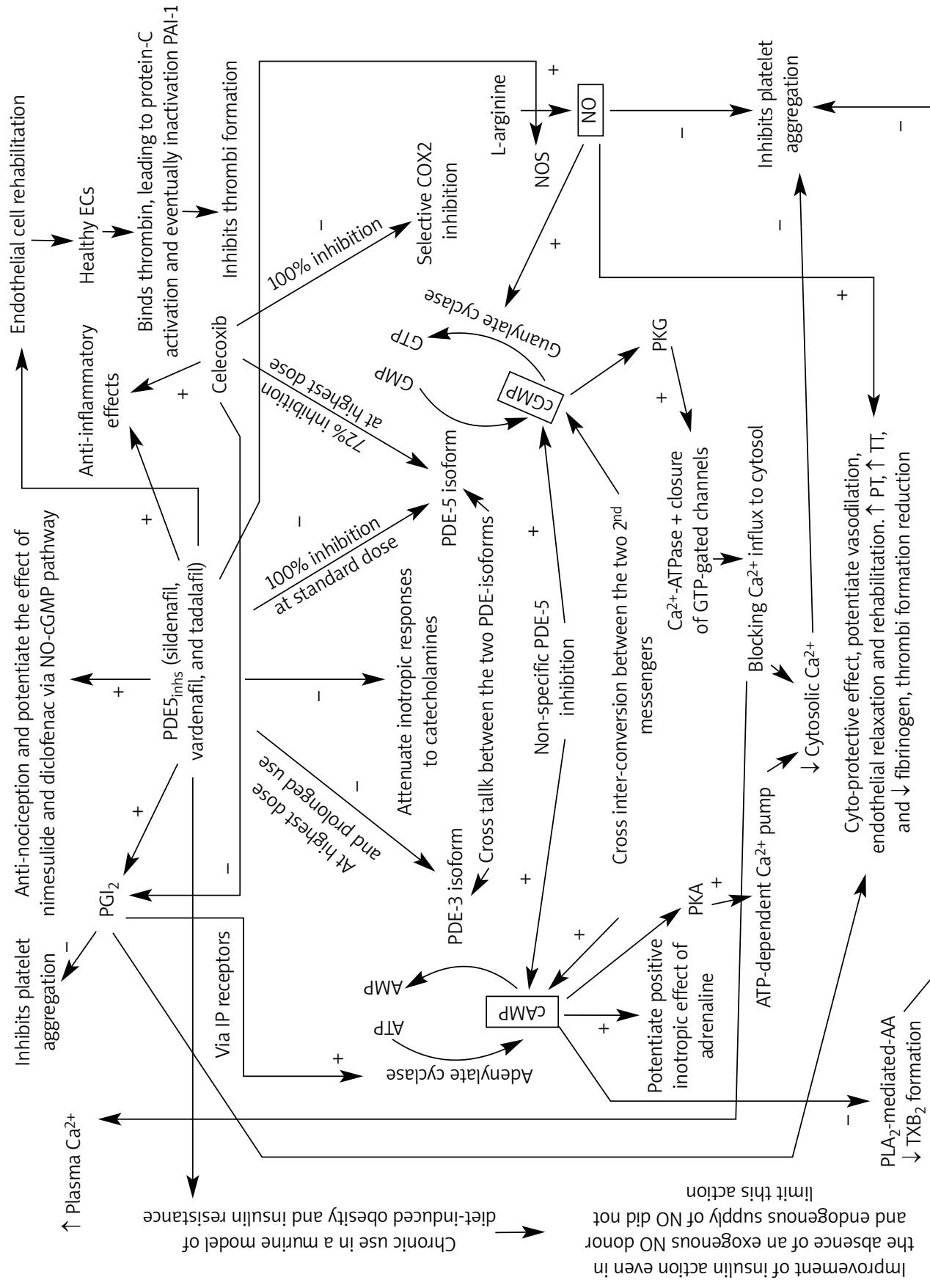


lial systemic effects $[9,13]$. Imbalance of eicosanoids, namely $\mathrm{TXA}_{2}$ and $P \mathrm{PI}_{2}$ biosynthesis, leads to myocardial ischemia (CVD) due to disrupted homeostasis [22].

The studied PDE5 $5_{\text {inhs }}$ significantly increased $\mathrm{PGF}_{1 \alpha}$ levels when compared either with their baseline data or with the saline group at the end of treatment. In contrast, PDE $5_{\text {inhs }}$ significantly decreased $\mathrm{TXB}_{2}$ levels when compared either with their baseline data or with the saline group at the end of treatment. The tadalafil group showed a lower increase in $\mathrm{PGF}_{1 \alpha}$ and lower decrease in $\mathrm{TXB}_{2}$ when compared with either sildenafil or vardenafil.

Sildenafil induces an insignificant blood pressure decrease through vasodilatation [23] and cardioprotection when infused in rabbits with ischemic injury [24]. Sildenafil and tadalafil have therapeutic benefits in patients with pulmonary arterial hypertension (PAH) [11] and congestive heart failure [25].

High levels of circulating systemic inflammatory markers are indicative for ED and its severity associated with endothelium-dependent vasoreactivity [26]. Sildenafil induces anti-nociception, and mimics the effect of the cyclooxygenase inhibitors through NO-cGMP pathway activation and cyclic GMP degradation inhibition [27].

Celecoxib, a selective COX-2 inhibitor, can induce PDE5 blockade in rat aorta, affecting the NO/cGMP signaling pathway and in guinea-pig heart induces coronary vasodilatation and increases coronary flow (CF) up to $72 \%$ by the administered dose $(200 \mathrm{nmol})$ in comparison with $100 \%$ CF increment by sildenafil [28]. COX-2 inhibitors bind with their polar sulfonamide side chain to a hydrophilic side COX-2 pocket and the effect of COX-2 inhibitors is time dependent [29]. Sildenafil and vardenafil have a sulfonyl side chain similar to that of celecoxib and that could suggest the anti-inflammatory effect of them via COX-2 inhibition through fitting the COX-2 pocket while tadalafil has a more bulky side chain without a sulfonyl group and this might explain the time-dependent lowering effect of tadalafil on $\mathrm{TXB}_{2}$. $\mathrm{TXA}_{2}$ and its stable metabolite $\mathrm{TXB}_{2}$ are essential regulators to amplify platelet activation, secretion and aggregation [6].

The significant decrease of $\mathrm{TXB}_{2}$ in this study could be explained as PDE5A inhibition augmenting CGMP leading to competitive inhibition of PDE3 elevating CAMP. Phospholipase-A-mediated arachidonic acid ( $A A$ ) and $T_{X B_{2}}$ formation will be inhibited by an elevation of cAMP. Consequently, cardioprotection of sildenafil is due to NOS enhancement, CGMP elevation and therefore CGMP-dependent protein kinase (PKG) activation through $\mathrm{K}^{+}$/ATP channel stimulation [30].

The present study showed that PDE5 ${ }_{\text {inhs }}$ significantly increase plasma calcium levels when com- pared with either their baseline data or the saline group at the end of treatment. The tadalafil group showed a slightly higher increase in calcium levels when compared with either sildenafil or vardenafil groups.

These results reflect a decrease in cytosolic calcium concentrations through closure of CGMP-gated channels and blocking of $\mathrm{Ca}^{2+}$ influx. The selective inhibition of CGMP-specific PDE5 by studied PDE5 $5_{\text {inhs }}$ results in elevation of CGMP concentrations activating PKG, which interacts with several proteins, including inositol triphosphate receptor, $\mathrm{Ca}^{2+}$-ATPase, closure of cGMP-gated channels and blocking of $\mathrm{Ca}^{2+}$ influx, decreasing cytosolic $\mathrm{Ca}^{2+}$ concentrations and leading to penile erection and inhibition of platelet aggregation [31, 32]. The $\mathrm{PGI}_{2}$ decreases cytosolic levels of calcium due to adenylyl cyclase activation and synthesis of CAMP that lower levels of cytosolic calcium to inhibit platelet activation [33].

Healthy intact ECs works as an anticoagulant membrane with fibrinolytic, anti-aggregative and anticoagulant effects through inhibition of fibrin formation by heparin-like molecules enhancing antithrombin III expression, tissue-type plasminogen activator (tPA) and inactivation of the extrinsic pathway by tissue factor pathway inhibitor [2]. The CAMP is a major mediator in controlling platelet activation; elevated CAMP leads to inhibition of platelet activation and tissue adhesion [34]. The $\mathrm{PGI}_{2}$ together with endothelium-derived relaxing factor (EDRF) shows synergistic action in inducing thrombo-resistance [35].

The current study showed that PDE5 ${ }_{\text {inhs }}$ significantly increase PT and TT when compared either with their baseline data or with the saline group at the end of treatment. The tadalafil group showed a lower increase in PT or TT when compared with either sildenafil or vardenafil. In contrast, PDE5 ${ }_{\text {inhs }}$ significantly decrease fibrinogen levels when compared either with their baseline data or with the saline group at the end of treatment.

These results are in disagreement with Michelakis et al. [36] and Robinson et al. [37], who found that sildenafil did not improve the fibrinolytic function and PT in coronary heart disease patients, even in patients using aspirin or warfarin. In addition, tadalafil had no significant hemodynamic effects on aspirin (bleeding time) and warfarin pharmacodynamics (prothrombin time) were not affected by vardenafil [38]. But the results of the current study are in line with Sheikh et al. [39], who reported a case of hemorrhoidal bleeding associated with sildenafil, Jackson [40], who showed that tadalafil has modest nitrate-like hemodynamic effects, and Berkels et al. [41], who found that $1 \mathrm{~h}$ after $100 \mathrm{mg}$ sildenafil administration, bleeding time was significantly prolonged and after $4 \mathrm{~h}$ was resolved toward control values. 
These paradoxical findings could be explained as being due to patients with chronic cardiovascular disease having damaged or partial intact endothelial cells with low capacity for expression of anti-thrombin III, heparin-like molecules, tissue factor pathway inhibitor, tissue-type plasminogen activator (tPA) and EDRF, and therefore the timedependent mild to moderate cyto-protective effect of PDE5 ${ }_{\text {inhs }}$ cannot affect hemodynamics or bleeding time in chronic CVD patients.

PDE5 ${ }_{\text {inhs }}$ might have a certain degree of crosstalk between PDE5 and PDE3 isoforms through the inhibitory effect of CGMP on PDE3 that elevates the CAMP/PKA pathway [42], and this explains why the prolonged use of PDE5 ${ }_{\text {inhs }}$ reduces thrombi formation as reported by Bischoff [8].

Chronic administration of sildenafil has no tachyphylaxis because it has no effect on NO bioavailability but it might activate the endothelial NOS by regulating the transduction pathway [43]. In CVD states, NO is also known to inhibit platelet activation/aggregation, vascular smooth muscle proliferation, leukocyte adherence, and low density lipoprotein oxidation [2]. Chronic use of PDE5 ${ }_{\text {inhs }}$ may induce endothelial rehabilitation even in the absence of an exogenous NO donor [9]. Sildenafil induces a relaxation effect on carbachol- pre-contracted human bladder dome smooth muscle through $\mathrm{K}^{+} / \mathrm{Ca}^{2+}$ and $\mathrm{K}^{+} /$ATP channel activation and cGMP/cAMP signaling pathways [44].

Men with erectile dysfunction who did not smoke had higher levels of plasma fibrinogen compared to both smokers and non-smokers without erectile dysfunction [45]. The mild decrease of fibrinogen in this study could be explained by the anti-inflammatory effect of PDE $5_{\text {inhs }}$ because fibrinogen is a protein and its synthesis in the liver increases during the acute phase of inflammation and injury.

As a result of $\mathrm{PGI}_{2}$-induced vasodilatation, inhibition of platelet aggregation, and PDE5 ${ }_{\text {inhs }}$ inhibition of thrombi formation, the blood pressured decreased and blood flow increased. This suggestion is supported by Kloner et al. [46] and Weinsaft et al. [47], who showed that tadalafil resulted in small changes in blood pressure, and in normal regions during increased workload, it increases myocardial blood flow significantly, while in diabetic ED patients with hypertension, sildenafil alone produces significant modest decreases in blood pressure of 8-10 mm Hg and not accompanied by any change in heart rate [48].

In the current study, the PDE5 ${ }_{\text {inhs }}$ studied groups showed a slightly different pattern to each other. This difference could be due to a difference in their selectivity, efficacy, side effects and pharmacokinetics [8] and they are dose-dependent drugs, which inhibit different PDE isoforms via many sec- ondary messengers resulting in new physiological action [13].

In conclusion, PDE5 ${ }_{\text {inhs }}$ has time-dependent mild to moderate endothelial cyto-protective, thromboresistance, anti-inflammatory, and anti-nociception effects. The prolonged use of PDE $5_{\text {inhs }}$ activates eNOS, increases $\mathrm{PGI}_{2}$ synthesis and decreases both TXA2 and fibrinogen, with a significant increase in PT and TT.

\section{Acknowledgments}

This study was not supported by any grants and all its costs were covered by the authors.

\section{Conflict of interest}

The authors declare no conflict of interest.

\section{References}

1. Thompsom IM, Tangen CM, Goodman PJ, Probstfield JL, Moinpour CM, Coltman CA. Erectile dysfunction and subsequent cardiovascular disease. JAMA 2005; 294: 2996-3002.

2. Kharbanda RK, Deanfield JE. Functions of the healthy endothelium. Coron Artery Dis 2001; 12: 485-91.

3. Cines DB, Pollak ES, Buck CA, Loscalzo J, Zimmerman GA, McEver RP. Endothelial cells in physiology and in the pathophysiology of vascular disorders. Blood 1998; 91: 3527-61.

4. Radwan ZM, Yamamah GA, Shaaban HH, Abdel-Rahman AMO, Ismaeil AA, Mostafa EM. Effect of different monotherapies on serum nitric oxide and pulmonary functions in children with mild persistent asthma. Arch Med Sci 2010; 6: 919-25.

5. Gryglewski RJ. Prostacyclin among prostanoids. Pharmacol Rep 2008; 60: 3-11.

6. Liu FC, Liao CH, Chang YW, Liou JT, Day YJ. Splitomicin suppresses human platelet aggregation via inhibition of cyclic AMP phosphodiesterase and intracellular $\mathrm{Ca}^{2+}$ release. Thrombosis Research 2009; 124: 199-207.

7. Watanabe R, Kishi Y, Sakita S, Numano F. Impaired NO release from bovine aortic endothelial cells exposed to activated platelets. Atherosclerosis 1997; 128: 19-26.

8. Bischoff E. Potency, selectivity, and consequences of non selectivity of PDE inhibition. Int J Impot Res 2004; 16: S11-4.

9. Ayala JE, Bracy DP, Julien BM, Rottman JN, Fueger PT, Wasserman DH. Chronic treatment with sildenafil improves energy balance and insulin action in high fatfed conscious mice. Diabetes 2007; 56: 1025-33.

10. Lin CS. Phosphodiesterases as therapeutic targets. Urology 2003; 61: 685-91.

11. Guazzi M, Tumminello G, Di Marco F, Fiorentini C, Guazzi MD. The effects of phosphodiesterase- 5 inhibition with sildenafil on pulmonary hemodynamics and diffusion capacity, exercise ventilatory efficiency and oxygen uptake kinetics in chronic heart failure. J Am Coll Cardiol 2004; 44: 2339-48.

12. Giuseppe MC, Aversa RA, Vitale C, Fabbri A, Fini M, Spera G. Chronic treatment with tadalafil improves endothelial function in men with increased cardiovascular risk. Eur Urol 2005; 47: 214-22. 
13. Reffelmann T, Kloner RA. Cardiovascular effects of phosphodiesterase 5 inhibitors. Curr Pharm Des 2006; 12 : 3485-94.

14. Behn D, Potter MJ. Sildenafil-mediated reduction in retinal function in heterozygous mice lacking the gamma-subunit of phosphodiesterase. Invest Ophthalmol Vis Sci 2001; 42: 523-27.

15. Hotchkiss AK, Pyter LM, Gatien ML, Wen JC, Milman HA, Nelson RJ. Aggressive behavior increases after termination of chronic sildenafil treatment in mice. Physiol Behavior 2005; 83: 683-8.

16. Radovits T, Bömicke T, Kökény $G$, et al. The phosphodiesterase-5 inhibitor vardenafil improves cardiovascular dysfunction in experimental diabetes mellitus. $\mathrm{Br}$ J Pharmacol 2009; 156: 909-19.

17. Pradelles P, Grassi J, Maclouf J. Enzyme immunoassays of eicosanoids using acetylcholine esterase as label: an alternative to radioimmunoassay. Anal Chem 1985; 57 : 1170-3.

18. Reinke $M$. Monitoring thromboxane in body fluids: a specific ELISA for 11-dehydrothromboxane B2 using a monoclonal antibody. Am J Physiol 1992; 262: E658-62.

19. Kessler G, Wolfman M. An automated procedure for the simultaneous determination of calcium and phosphorus. Clin Chem 1964; 10: 686.

20. Mackie IJ, Kitchen S, Machin SJ, Lowe GD. Guidelines on fibrinogen assays. Br J Haematol 2003; 121: 396-404.

21. Dacie JV, Lewis SM. Tests for acute phase response. In: Practical haematology. $8^{\text {th }}$ ed. Churchill Livingstone, New York 1996; 559-63.

22. Schrör K. Antiplatelet drugs: a comparative review. Drugs 1995; 50: 7-28

23. Ishikura F, Beppu S, Hamada T, Khandheria BK, Seward JB, Nehra A. Effects of sildenafil citrate (Viagra) combined with nitrate on the heart. Circulation 2000; 102: 2516.

24. Das A, Ockaili R, Salloum F, Kukreja RC. Protein kinase C plays an essential role in sildenafil-induced cardioprotection in rabbits. Am J Physiol Heart Circ Physiol 2004. 286: $\mathrm{H} 1455-60$

25. Bocchi EA, Guimaraes G, Mocelin A, Bacal F, Belotti G, Ramires JF. Sildenafil effects on exercise, neuro hormonal activation and erectile dysfunction in congestive heart failure: a double-blind, placebo-controlled, randomized study followed by a prospective treatment for erectile dysfunction. Circulation 2002; 106: 1097-103.

26. Vlachopoulos C, Rokkas K, loakeimidis N, Stefanadis C. Inflammation, metabolic syndrome, erectile dysfunction, and coronary artery disease: common links charalambos. Eur Urol 2007; 52: 1590-600.

27. Patil CS, Jain NK, Singh A, Kulkarni SK. Modulatory effect of cyclooxygenase inhibitors on sildenafil-induced antinociception. Pharmacology 2003; 69: 183-9.

28. Klein T, Eltze M, Grebe T, Hatzelmann A, Kömhoff $M$. Celecoxib dilates guinea-pig coronaries and rat aortic rings and amplifies NO/cGMP signaling by PDE5 inhibition. Cardiovasc Res 2007; 75: 390-7.

29. Lanzo CA, Sutin J, Rowlinson S, et al. Fluorescence quenching analysis of the association and dissociation of a diarylheterocycle to cyclooxygenase-1 and cyclooxygenase-2: dynamic basis of cyclooxygenase-2 selectivity. Biochemistry 2000; 39: 6228-34

30. Xing M, Post S, Ostrom RS, Samardzija M, Insel PA. Inhibition of phospholipase A2-mediated arachidonic acid release by cyclic AMP defines a negative feedback loop for $\mathrm{P} 2 \mathrm{Y}$ receptor activation in Madin-Darby canine kidney D1 cells. J Biol Chem 1999; 274: 10035-8.
31. Corbin JD, Francis SH. Cyclic GMP phosphodiesterase-5: target of sildenafil. J Biol Chem 1999; 274: 13729-32.

32. Jackson SP, Nesbitt WS, Kulkarni S. Signaling events underlying thrombus formation. J Thromb Haemost 2003; 1: 1602-12.

33. Hoffbrand AV. Essential haematology. Blackwell Science, Oxford 2002; 243-45.

34. Kimura Y, Yasunaga K. Interaction of prostaglandin and cyclic AMP involved in regulation of platelet function. Nippon Ketsueki Gakkai Zasshi 1980; 43: 1130-8.

35. Sinzinger H, Fitscha P, O'Grady J, Rauscha F, Rogatti W, Vane JR. Prostaglandin E, and isosorbide dinitrate, a donor of nitric oxide, synergize in inducing thromboresistance in patients with peripheral vascular disease. Lancet 1989; i: 627-8.

36. Michelakis E, Tymchak W, Archer S. Sildenafil: from the bench to the bedside. CMAJ 2000; 163: 9.

37. Robinson SD, Ludlam CA, Boon NA, Newby DE. Phosphodiesterase type 5 inhibition does not reverse endothelial dysfunction in patients with coronary heart disease. Heart 2006; 92: 170-6.

38. Gupta M, Kovar A, Meibohm B. The clinical pharmacokinetics of phosphodiesterase-5 inhibitors for erectile dysfunction. J Clin Pharmacol 2005; 45: 987.

39. Sheikh RA, Yasmeen S, Prindiville TP. Hemorrhoidal bleeding associated with sildenafil. Am J Gastroenterol 2001; 96: 2518-9.

40. Jackson G. Hemodynamic and exercise effects of phosphodiesterase 5 inhibitors. Am J Cardiol 2005; 96: $32 \mathrm{M}-6 \mathrm{M}$.

41. Berkels R, Klotz T, Sticht G, Englemann U, Klaus W. Modulation of human platelet aggregation by the phosphodiesterase type 5 inhibitor sildenafil. J Cardiovasc Pharmacol 2001; 37: 413-21.

42. Schwarz ER, Kapur V, Rastogi S, Rosanio S. The effect of chronic phosphodiesterase-5 inhibitor use on different organ systems. Int J Impot Res 2007; 19: 139-48.

43. Behr-Roussel D, Gorny D, Mevel K, et al. Chronic sildenafil improves erectile function and endothelium-dependent cavernosal relaxations in rats: lack of tachyphylaxis. Eur Urol 2005; 47: 87-91

44. Oger S, Behr-Rousse D, Gorny D, et al. Signalling pathways involved in sildenafil-induced relaxation of human bladder dome smooth muscle. Br J Pharmacol 2010; 160: 1135-43.

45. Sullivan ME, Miller MA, Bell CR, et al. Fibrinogen, lipoprotein (a) and lipids in patients with erectile dysfunction. A preliminary study. Int Angiol 2001; 20: 195-9.

46. Kloner RA, Mitchell M, Emmick JT. Cardiovascular effects of tadalafil in patients on common antihypertensive therapies. Am J Cardiol 2003; 92: 47M-57M.

47. Weinsaft JW, Hickey K, Bokhari S, et al. Effects of tadalafil on myocardial blood flow in patients with coronary artery disease. Coron Artery Dis 2006; 17: 493-9.

48. Bhalla A, Singh R, Gautam CS, Sachdev A. Sildenafil citrate in diabetics with hypertension and erectile dysfunction. The Internet Journal of Internal Medicine ISSN 2003; 15288382. 